\title{
Making a Sense of Multicultural Community: Ansan, Korea
}

\author{
Young-Sang Yim and Jin-Young Kim
}

\begin{abstract}
Korea has been undergoing an unprecedented and the largest-scale multicultural phenomenon in history. Since the mid-2000s, an influx of marriage immigrants and migrant workers has have influence on Korea socio-demographically as well as politically. In this course, Ansan in Gyeonggi Province has emerged as a city that implements the most advanced and liberal multicultural policies. Accordingly, this study aims to find the factors that drive Ansan to stand on the front of integrating multicultural Korea and to understand its background as well as the process of establishing multiculture in the city.
\end{abstract}

Index Terms-Ansan multicultural village special zone, ansan migrant community service center, multicultural family, borderless village movement.

\section{INTRODUCTION}

THE concept of multiculture had been a new term for most of Korean people until the mid-2000s when a number of marriage immigrants came into Korea. Throughout the Korea's modern history, particularly in $60 \mathrm{~s}$ and $70 \mathrm{~s}$ of military dictatorship, the ghost of a single-race nation hovered around Korean society as a means of control and rule. This rigid frame started to change as internal problems such as low birth-rate and vacantization of rural areas according to industrialization as well as globalization that activates international migration. As mentioned in many of the previous researches, Korea had to face multi-phenomena in the midst of rapidly-changing age, leading itself to multicultural nation from one-race country. No matter how unfamiliar it sounds, it is not overstated that most of Korean people encounter the term 'multiculture' at least once a week.

TABLE I: ALIEN RESIDENT LIVING IN ANSAN (2013)

\begin{tabular}{|c|c|c|c|}
\hline & no. of males & no. females & Total no. \\
\hline City of Ansan & 28,374 & 20,875 & 49,249 \\
\hline Sangrok-gu & 4,080 & 4,115 & 8,195 \\
\hline Danwon-gu & 24,294 & 16,760 & 41,054 \\
\hline
\end{tabular}

In light of the statistics, it provides a valid statement. The population of Ansan is 381,520 in Sangrok-gu District and 323,817 in Danwon-gu District, reaching 705,337 in total. Considering the foreign population in Ansan, the number is significant compared to other cities of Korea, accounting for 7\% of the population of Ansan. In particular, that of Danwon-gu District alone consists of $5.8 \%$. Unlike other conventional multicultural countries, there is still relatively a small proportion of foreign population in Korea, making

Manuscript received September 19, 2015; revised November 5, 2015.

The authors are with the Hankuk University of Foreign Studies, Korea (e-mail: staci21@naver.com). about $3 \%$ of the whole population. Thus, the number of alien residents in Ansan is more than twice. The residents' nationality is diverse from America to Republic of Benin. In this regard, Ansan has implemented the most advanced and liberal multicultural policies in the nation. Consequently, it played an important role in terms of establishing a multicultural society that has been introduced in recent years. Accordingly, this study aims to look through the process of settling multicultural policies and implementation of relating laws. In addition, it will find a way to bridge between Korean locals and alien residents by introducing successful cases that have been executed.

\section{BACKGROUNDS OF THE Multicultural COMMUNITY IN ANSAN}

\section{A. Overview}

Ansan lies on the west coast of the Korean Peninsula, neighboring Siheung and Anyang in the north, Gunpo and Uiwang, Suwon in the east, Hwaseong in the south. In the mid-70s, a large-scale industrial cluster was formed in the Ansan area. Along with the cluster, its transport access was improved. Since another industrial complex called the Sihwa Industrial Cluster developed around Ansan, the city grew, having as large population as close to 800,000 . In the clusters, more than 170,000 people work in various kinds of factories or companies; the number of businesses is roughly 8,200 . On the contrary to its industrial image, the city has $72 \%$ of green space ratio and more than 270 parks with the highest new and renewable energy supply ratio in the nation.

In the early 1980s, as the industrial complexes were operated in earnest, neighboring Wongok-dong developed as well. The people who flocked into the area to look for jobs settled down in Wongok-dong, Ansan. The reason for this accounts for the development of a collective housing complex. Coming into 1990s, Wongok-dong changed its face dramatically in demography. The Korean population in the area decreased in half compared to that of 1980s. In general, Korea's economy underwent a rapid and dramatic change from the secondary industry to the tertiary. To top it off, the economic stagnation was prolonged. It was the time that Wongok-dong which was almost abandoned by Koreans turned out to be 'the Capital of Migrant Workers.' After mid-1990s, due to the influx of migrant workers, Wongok-dong spontaneously became a multicultural district In Wongok-dong, there are affluent jobs, low living cost, many ethnic communities and networks, religious organizations. As the number of migrant workers flew into Wongok-dong, schools, NGOs, public service infra such as banks and welfare offices and other convenient facilities have mushroomed. Gyeonggi Province designated Wongok-dong 
of Ansan in 2009 as the Multicultural Village Special Zone as the intra relating migrant workers increased. Ansan has utilized multiculture as its city brand. The purpose of the designation is to priorly reflect the policies for immigrants and support the multicultural community to settle down on a stable basis. Along with it, it is projected to boost the local economy by attracting tourists [1].

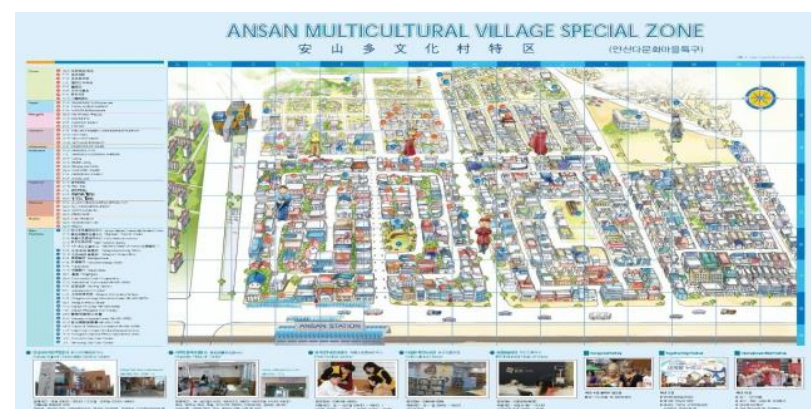

Fig. 1. The map of the multicultural village special zone in Wongok-Dong.

\section{B. Present Conditions}

The Multicultural Village Special Zone is located at Wongok-dong in Danwon-gu of Ansan, Gyeonggi Province. The area is about $367,541 \mathrm{~m}^{2}$. The Province planned to invest 18.6 billion won(16,641,316 USD) in the village from 2008 to 2013. With this particular plan, the multicultural village is able to establish relating infra such as Ansan Migrant Community Service Center, public transportation transit center, street sign improvement (using foreign language and Korean side by side) and so on. In addition, the meeting plaza was built in the middle of the village to hold concerts or flea market as well as meeting point. The street that crosses the village is specialized as the Street of Multicultural Food and Car-Free. There are more than 20 model restaurants and 200 general restaurants. Many events and festivals are also held in the village. Ansan enacted 'Together Day' in 2008. On May 20 , the city holds a ceremony, inviting Korean and foreign delegates. Every October there is the International Unity Festival held in the village to make a harmonious community. Furthermore, many immigrant groups hold their traditional festival such as Naadam of Mongolia, Songkran of Thailand, Boishakhi Mela of Bangladeshi and Indonesia Day of Indonesia. Ansan is the first city in Korea, which enacted a city ordinance that ensures equal treatment of immigrants and promoted their human rights in 2007.

As of August 2014, the number of alien residents in Ansan was 69,500 accounting for $9 \%$ of the population of Ansan with an increase by almost two times over the last six years from 35,000 in 2008 to 69,500 in 2014 and these increases in the population of alien residents are expected to continue. Ansan is a region with the highest ratio of foreign population throughout the country and the first alien resident center in South Korea was established in Wongok-dong, Ansan. The Alien Resident Center was prepared for active responses to the administrative demand occurring due to the coexistence of diverse cultures and is being operated under direct control of the Ansan government. The services provided by this center including various administrative services, leisure related services, medical services, interpretation services, and money remittance services are regarded as cases for benchmarking by other local government. The Alien
Resident Center is an institution directly managed by the Ansan government where more than 30 staff members work. This center operates mobile patrol teams from 18:00 to 04:00 next day and many alien residents are included in the mobile patrol teams. In addition, this center provides life-long learning programs to residents with diverse nationalities without any off day. Since the Alien Resident Center provides one-stop administrative services as well as providing various convenience facilities and free education on computer and bakery skills, etc., 21,000 foreigners visit the center on average per month. Furthermore, this center supports diverse national cultural events such as Sonkran Festival of Thailand, Independence Day of Indonesia, and water festival called Beoneomttuk of Cambodia, operates the only multi-culture public relations and learning center among local governments and a multi-culture street as stages of understanding of multi-culture through experience.

As of 2014, 1454 businesses were in operation in the special multi-culture village zone and of them, 435 were foreign businesses and 175 were foreign restaurants from 15 countries. Despite the economic recession in South Korea, the number of businesses in the shopping district of the special multi-culture village zone and the special multi-culture village zone is becoming a capital of foreign workers on which immigrant workers converge from various regions in the capital zone every weekend.

Immigrant workers from the islamic world including Indonesia and Pakistan with strong religious identity visit the special multi-culture village zone to have religious rituals in the mosque in Wongok-dong and buy halal foods which are islamic food materials. More immigrants visit Ansan because there is an interpretation counseling center in the Alien Resident Center so that immigrant who do not know real states of affairs in South Korea can ask everything and shops in the special multi-culture village zone have staff members who explain things in detail in their native languages.

The active inflows of immigrants are helpful for improvement of the infra in the region. Currently, the regional economy in the special multi-culture village zone is active thanks to foreign workers and urban style living houses are actively reconstructed to accommodate immigrant workers. Other programs provided by the Alien Resident Center are as follows. To help the social settlement of multicultural families including marriage immigrants in the region, the center advised that diverse projects are planned such as marriage immigrant education projects including: education on Korean language by level; multi-culture integrating education; professional occupational training education, settlement support projects including; family counseling; sharing service group operation ; improvement of perception of multi-culture families, children education projects including: multicultural family children language development education; language gifted children classroom, family support projects including: customized type integrated case management; prevention for health; support for families in crisis. We Start supporters, and community integration services including: world culture cafe; world festivals; sharing market 'Kidari Market' operation; prenatal educational care music concerts.

In the course, the Migrant Community Service Center was 
founded in 2008. The Center provides a wide range of services for immigrants from educative courses to public health services as well as other cultural experiential opportunities. It has become a Mecca of multiculture in Korea. The immigrants participate in various activities and at the same time they get help to break cultural barriers and adjust to Korean society in early stages.

TABLE II: FACILITY INFORMATION

\begin{tabular}{|l|c|l|}
\hline \multicolumn{1}{|c|}{ Floors } & Area & \multicolumn{1}{c|}{ Facilities } \\
\hline Gross area & $1,828 \mathrm{~m}^{2}$ & $\begin{array}{l}1 \text { floor underground } \\
\text { /3 fl. above ground. }\end{array}$ \\
\hline Ground fl. & $472.61 \mathrm{~m}^{2}$ & $\begin{array}{l}\text { Community Offices, Multicultural } \\
\text { Library, Machine/Electricity Control } \\
\text { Center, Global Children Center, Lecture } \\
\text { rooms }\end{array}$ \\
\hline 1 st fl. & $\begin{array}{l}\text { Free Medical Service Center(Danwon } \\
\text { community Health Center, Wongok } \\
\text { Branch), Foreign Exchange Transaction } \\
\text { Center, meeting room, outdoor } \\
\text { performance stage }\end{array}$ \\
\hline 2nd fl. & $494.33 \mathrm{~m}^{2}$ \\
\hline 3rd fl. & $378.02 \mathrm{~m}^{2}$ & $\begin{array}{l}\text { Migrants' help Call, conference room, } \\
\text { lecture theater, computer room, offices }\end{array}$ \\
\hline 4th fl. & \multicolumn{3}{|c|}{ Roulture house (multipurpose) } \\
\hline \multicolumn{2}{|c|}{ The Homepage of the Migrant Community Service Center }
\end{tabular}

As seen on Table II, the Center is not a huge building but very feasible for providing efficient services from healthcare and cultural activities to education and recreation by aiding visitors with one-stop service. Relative to the size of the Korean economy, the programs and facilities of the Center may have a long way to develop, being in infancy, however, the Center has been a cradle to foster the Korea's early multicultural community so far.

\section{Future Issues AND Challenges AHEAD}

On the contrary to Ansan's efforts to set a stepping-stone for a very advanced multicultural community, the public sentiment may be a little different from what Ansan has expected. According to the report [2], the Ansan citizens are concerned about safety and its negative image. In addition, the multicultural-city brand is not perceived as a means of boosting its economy. The reason for this response is attributed to the result that reflects the increasing foreign crime rate. In 2015, the Ansan government conducted a consciousness survey with 500 citizens that visited the special multi-culture village zone in Wongok-dong, Danwon-gu to establish multi-culture centered city development strategies and according to the results, $61.3 \%$ of the respondents showed negative opinions such as 'dangerous and dirty.' The citizens worried about problems such as public order deterioration due to increases in foreigners $(52.2 \%)$, living environment deterioration such as basic order violation $(19.4 \%)$, degradation on educational environments due to multinational family children (15.2\%), relative alienation of natives $(6.8 \%)$, traffic congestion due to floating populations $(5.8 \%)$. However, as positive effects expected in case Ansan grows into a central city for multi-culture families, the citizens referred to the establishment of a basis for multicultural society (32.6\%), expansion of opportunities for cultural enjoyment (25.0\%), establishment of national support infra $(17.2 \%)$, revenue increases through becoming tourism resources (16.8\%), and real estate value rise $(4.4 \%)$. As measures to relieve negative images, the citizens presented the construction of multi-culture community house by country in the special multi-culture village zone, the formation of a food street to satisfy five senses, permanent festival operation, the organization of a Wongok-dong resident autonomy committee. In addition, the citizens pointed out that exchanges with foreigners should be activated to remove repulsion and educational and cultural programs for multi-cultures should be continuously developed.

Accordingly, to relieve the negative perception of the special multi-culture village zone, the Ansan government organized Won-gok special patrol teams that include alien residents to conduct patrols at night and vulnerable hours at daybrea, periodically provides education for basic order observance and crime prevention to learners participating in Alien Resident Center education programs jointly with related institutions and departments, and continuously improves environments that induce crimes such as installing more CCTVs and security lights in vulnerable regions.

The Korean residents living in Ansan area seem to hierarchize the Korean-the immigrant class socio-demographically. About 80 nationals are placed at the periphery of the society while Koreans at the core or majority. Thus, Wongok-dong, Ansan is prone to highlighting the cultural difference between native Koreans and immigrants [3]. However, at the same time, the Korean living in Wongok-dong has receptivity and exclusiveness. For instance, they actively participated in playing a commercial activity, accepting immigrants as consumers. In addition, many religious and civic groups are taking a duty for immigrants. Along with these, the local government recognizes the importance of immigrant residents, supporting them by enforcing many policies. In contrast, the Korean residents in Wongok-dong are likely to complain about crimes relating to immigrants, disorderly traffic, littering and other misdemeanors [4].

There are problems in operating the Migrant Community Service Center even if it is managed by the Ansan Office. The budget is always too short to establish a variety of courses and programs and too small to hold a large audience as well. As for civic groups, they have shortage of budget and lack of promotion and skillful human resource. Consequently, the migrant workers living in Wongok-dong are hard to take part in the programs such as cultural activities and Korean language education. Due to the reason why they came to Korea, it is evident that they are less willing to enjoy their spare time than use the time to earn more money [5].

\section{CONCLUSION}

Ansan has set a milestone for establishing multicultural society in terms of policy-making and practical implementation. Accordingly, compared to other local governments, its status related to multiculture is not even measured up. With winning many administrative awards, Ansan has created the city brand of multiculture based on the confidence and experiences. Yet, as soon as it's getting out of political frame, the illusions that were hidden in its fancy reputation reveal brutal truths right away [6]. 
To many Korean people, multiculture degenerated into a modifier for poor and less educated marriage immigrants from developing countries in Southeast Asia, so multiculture in Korea is implicitly categorized as a social class. In fact, there are a number of informative courses held in the Migrant Community Service Center, yet, many migrant workers could not take part in the courses due to the livelihood [7]. The classes are opened during the daytime since the supervisors are public officials working from 9am to $5 \mathrm{pm}$. Many migrant workers are likely to find trouble adapting to Korea's highly competitive education system. Despite the fact that they need more aid regarding educating their child, a majority of classes are for acquire language competence or living cultural information.

In Ansan, there are many NGOs which have long history to cumulate know-how's and human resource. The networking between the NGOs and the public organizations has to be properly set on. Based on it, more efficient and organic multicultural policy will be established through cooperative relationship.

\section{REFERENCES}

[1] Ansan City Office Homepage. [Online]. Available: www.iansan.net

[2] S. Lee, "A survey on space consciousness in multicultural areas for residential sustainability-focused on Siheung city an Ansan city," Journal of Design Association, vol. 28, no. 2, pp. 121-134, May, 2015.

[3] D. Lui, "A critical approach to local multicultural spaces in Korea: Focusing on the transformations in Ansan and Garibong neighborhoods," Cultural Study of Northeast Asia, vol. 27, pp. 5-14, Jun. 2011.

[4] M. Kim, "Students' recognition of multicultural society and its implication about geography education: A case study of Ansan," Modern Society and Multiculture, vol. 2, no. 1, pp. 234-269, Jun. 2012.
[5] Y. E. Yim, S. Y. Lee, and N. K. Kim, "A study on the current status of the centers for migrant workers and policy proposals in the era of transnation: A case of Ansan city," Korean-Japanese Museum and Global Diaspora, vol. 5, pp. 325-358, Feb. 2011.

[6] K. S. Oh, "Idealism and reality of multicultural hub city: Experience of Wongok-dong, Ansan," The Land, vol. 342, pp. 39-45, Apr. 2010.

[7] S. W. Song, S. Y. Lee, and N. K. Kim, "A study on the current status of the migrant workers' support problems at the level of a local government: A case of Ansan city," Diaspora Studies, vol. 5, no. 2, pp. 29-62, Dec. 2011.

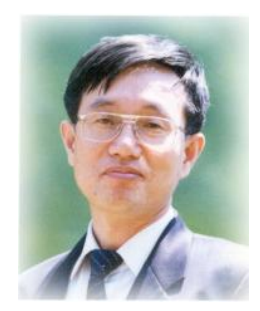

Young-Sang Yim was born in Seoul, Korea in 1952. He received the B.A. M.A. and Ph..D degrees in history from Seoul National University in 1988. He started his academic career as a professor at Korea Air Force Academy in 1974 and transferred to Hankuk University of Foreign Studies in 1982. Since then he has served in the Department of History. In 2015, he made the Department of Knowledge Contents to live up to the demand of rapid-changing society. He is currently in charge of the Knowledge Contents Department as a chair. He served as the Academic Association of Korean Diaspora as a chair for two years from 2012-2013.

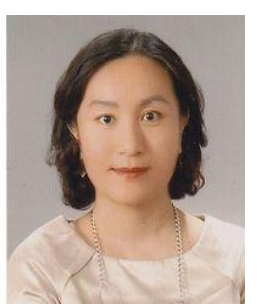

Jin-Young Kim was born in Seoul, Korea. She received the B.S. in biology at University of Southern California, USA, the M.A. and the Ph..D in English Education and cultural contents at Hankuk University of Foreign Studies. She has been working as an adjust professor at the same university. 